3 Федеральный закон от 27.07.2006 № 149-Ф3 (ред. от 02.12.2019) "Об информации, информационных технологиях и о защите информации" (с изм. и доп., вступ. в силу с 13.12.2019) // Российская газета. № 165. 29.07.2006.

${ }^{4}$ Камалова Г.Г. Соотношение правовых режимов служебной и профессиональной тайн // Вестник Южно-Уральского государственного университета. № 4. 2016. С. 87-94.

5 Павлов А. В. К вопросу о законодательном определении понятий профессиональных тайн // Сибирское юридическое обозрение. № 1. 2019. С. 13-19.

\title{
PROBLEMS OF FIXING THE LEGAL DEFINITION OF "PROFESSIONAL SECRET"
}

\author{
(c) 2020 Krylova Ekaterina Pavlovna \\ Student \\ (C) 2020 Churakova Ekaterina Nikolaevna \\ Candidate of Law, Associate Professor \\ Samara State University of Economics \\ E-mail: katapavlovna@gmail.com, churakovaen@gmail.com
}

Keywords: professional secrecy, legal regime, information protection, legal regulation, information law.

This article discusses the concept of professional secrecy and the legislative approach to regulating relations related to the use of information related to professional secrecy. Problematic aspects are identified, and the existing practice of legal regulation is evaluated. The authors concluded that the Institute of legal protection of professional secrets in Russia is insufficiently developed, and formulated proposals for improving information legislation.

УДК 368

Код РИНЦ 06.00.00

\section{ПРОБЛЕМЫ ПРАВОВОГО СТАТУСА АКТУАРИЯ И ОСУЩЕСТВЛЕНИЯ АКТУАРНОЙ ДЕЯТЕЛЬНОСТИ}

\author{
(C) 2020 Кузнецова Екатерина Сергеевна* \\ студент \\ Самарский государственный экономический университет \\ E-mail: ek.cudryashova@yandex.ru
}

Ключевые слова: актуарий, ответственный актуарий, актуарное заключение.

Статья посвящена анализу правового статуса актуария, в том числе проблемам, которые встречаются при осуществлении актуарной деятельности. Автор рассматривает данные проблемы в совокупности и дает их общую оценку, а также предлагает пути их разрешения.

\footnotetext{
* Научный руководитель - Зубкова Мария Николаевна, кандидат юридических наук, доцент.
} 
Сегодня одной из приоритетных задач государства является повышение работоспособности и надежности финансового рынка, важной сферой которого является актуарная деятельность. Следовательно, важным субъектом в данной области является актуарий. В целях правового урегулирования основ деятельности актуариев был принят ФЗ от 02.11.2013 № 293-Ф3 "Об актуарной деятельности в Российской Федерации"" (далее - Ф3 "Об актуарной деятельности").

Однако, как следовало ожидать, принятый закон не устранил все имеющиеся вопросы и проблемы. До сегодняшнего дня не устранены пробелы, связанные с правовым статусом актуария, также в ФЗ "Об актуарной деятельности" отсутствуют четкие требования к актуарному заключению. Кроме того, существует проблема профессиональной подготовки актуариев. Так, в настоящее время учебные заведения, имеющие программы по обучению указанных специалистов расположены преимущественно в Москве и Санкт-Петербурге. При этом соискатели данной профессии, проживающие в отдаленных районах, таких как Дальний Восток, Сибирь фактически лишены возможности пройти профессиональную подготовку, а финансовые организации, нуждающиеся в актуарном оценивании, сталкиваются с проблемой привлечения актуария к работе в указанных районах. В связи с этим в указанной статье будут рассмотрены проблемы, связанные с осуществлением актуарной деятельности и определением правового статуса актуария.

Еще более чем за десять лет до принятия Ф3 "Об актуарной деятельности" обсуждался вопрос установления правового статуса актуария. Ни у кого не возникало сомнений в важности данного субъекта при определении вероятности наступления рисков, управлении данными рисками, формировании резервов, установлении тарифов.

Объективная оценка деятельности финансовой организации управление ее рисками является важным не только для самого субъекта предпринимательской деятельности, но для органа, осуществляющего надзор в данной сфере - ЦБ РФ². Так указанный орган осуществляет контроль финансовой надежности некоторых профессиональных участников рынка.

Стоит отметить, что актуарная деятельность осуществляется обязательно или добровольно. Законодательством установлен ограниченный круг субъектов, для которых необходимо обязательное актуарное оценивание. У данных субъектов можно выделить общие признаки и особенности.

Во-первых, данные субъекты прямо поименованы в ФЗ "Об актуарной деятельности" (к таковым относятся ЦБ РФ, страховые организации, общества взаимного страхования, негосударственные пенсионные фонды).

Во-вторых, деятельность указанных лиц носит рисковый характер.

В соответствии с п. 1 ст. 2 ГК РФ рисковость является признаком предпринимательской деятельности, следовательно, можно сделать вывод, что потребителем актуарных услуг являются исключительно коммерческие организации. Однако, не стоит ограничиваться таким узким толкованием. Некоторые некоммерческие юридические лица также нуждаются в услугах актуария, например, общества взаимного страхования. Так в деятельности указанного субъекта существует риск наступления определенных событий, в связи с которым возникают соответствующие обязательства. Поэтому для обществ взаимного страхования также важна оценка рисков. Таким образом, не только предприниматели нуждаются в оценке своей деятельности актуарием. 
В-третьих, рассматриваемые субъекты имеют финансовые обязательства в отношении иных лиц. Данный признак предопределяет обязанность субъектов обязательного актуарного оценивания иметь достаточные резервы для покрытия своих обязательств перед потребителями их услуг ${ }^{3}$.

В подтверждение того, что все вышеуказанные признаки применимы к субъекту обязательного актуарного оценивания, приведем пример на одном из таких субъектов. Страховая организация является субъектом, в отношении которого обязательно должна осуществляться актуарная деятельность, так как она прямо поименована в ФЗ "Об актуарной деятельности", осуществляет предпринимательскую деятельность и имеет финансовые обязательства перед третьими лицами, страхователями, выгодоприобретателями по договору страхования.

В законодательстве прямо не поименована деятельность по добровольному актуарному оцениванию. Однако введя положение об обязательном актуарном оценивании в отношении конкретных субъектов, законодатель оставил возможность и добровольного актуарного оценивания. Отметим, что каждый субъект гражданского оборота в той или иной степени несет финансовые риски, а значит, может нуждаться в актуарном оценивании. Таким образом, позиция законодателя о допустимости добровольного актуарного оценивания вполне обоснована и справедлива в современных экономических условиях 4 .

Рассмотрим подробнее статус субъекта, непосредственно осуществляющего актуарную деятельность на профессиональной основе.

Ф3 "Об актуарной деятельности" выделяет два вида актуариев: актуарий и ответственный актуарий. Понятие и правовой статус каждого из этих субъектов определены в указанном нормативно-правовом акте, в связи, с чем в литературе не наблюдается споров относительно указанных определений.

"Актуарий - физическое лицо, осуществляющее на профессиональной основе в соответствии с трудовым договором или гражданско-правовым договором актуарную деятельность и являющееся членом саморегулируемой организации актуариев.

"Ответственный актуарий" - актуарий, сведения о котором внесены уполномоченным органом в единый реестр ответственных актуариев, который имеет право осуществлять в соответствии с трудовым договором или гражданско-правовым договором подготовку актуарного заключения для направления его в уполномоченный орган и несет ответственность за обоснованность содержащихся в таком заключении выводов в соответствии с законодательством Российской Федерации".

Проанализировав вышеизложенные определения можно выделить общие черты рассматриваемых субъектов. Так они могут осуществлять свою деятельность на основе как гражданско-правового, так и трудового договоров. И один и другой должны являться членами саморегулируемой организации. Однако сведения в реестр вносятся только относительно ответственного актуария. Также только ответственный актуарий вправе готовить актуарное заключение, неся определенную ответственность за его достоверность, в то время как актуарий осуществляет лишь текущий контроль за деятельностью организации.

Исследовав в совокупности иные правовые нормы Ф3 "Об актуарной деятельности", касающиеся правового статуса актуария и ответственного актуария также можно выделить следующие общие черты: 
- к обоим субъектам предъявляется требование о наличии высшего математического или экономического образования;

- ограничением приобретения статуса актуария и ответственного актуария является неснятая или непогашенная судимость за преступления в сфере экономики, а также за преступления средней тяжести, тяжкие и особо тяжкие преступления.

Исходя из более сложного статуса ответственного актуария, можно сделать логический вывод, что к нему предъявляются дополнительные, более строгие требования, чем к актуарию.

Так, он должен иметь подтвержденный саморегулируемой организацией актуариев стаж работы в области проведения актуарного оценивания и (или) актуарных расчетов не менее чем три года из последних пяти календарных лет, соответствовать дополнительным требованиям к квалификации ответственных актуариев и иметь аттестацию саморегулируемой организацией актуариев.

Помимо вышеуказанных требований к ответственному актуарию, осуществляющему актуарное оценивание на основании гражданско-правового договора, предъявляется требование об обязательном заключении договора страхования гражданской ответственности.

При этом стоит отметить, что указанный перечень требований к субъектам актуарного оценивания не является исчерпывающим. Так саморегулируемые организации могут предъявлять дополнительные требования к своим участникам. Так, например, саморегулируемой организацией к актуарию может быть предъявлено дополнительное требование относительно теоретических познаний и практических навыков в отдельных областях (бухгалтерский учет, математическая статистика, страхование и т.д.).

Рассматривая признаки субъекта актуарной деятельности уже отмечалось, что такая деятельность может осуществляться на основании трудового или гражданско-правового договора.

Но справедливо также заметить, что это не единственное основание для осуществления актуарного оценивания. Так, актуарий может действовать в связи с принятием Правительством РФ административного акта-распоряжения. Такой документ может быть издан в связи с необходимостью оценки финансовой деятельности организаций, созданных Российской Федерацией, а также организаций, которые были созданы для выполнения задач, поставленных перед федеральными органами государственной власти.

Говоря об ограничениях правового статуса ответственного актуария можно заметить, что данный не может являться учредителем (участником) организации, деятельность которой он оценивает. Кроме того, он также не может занимать должность руководителя или главного бухгалтера в этой организации. Пытаясь установить полную независимость ответственного актуария законодатель пошел еще дальше, так ответственному актуарию запрещено состоять в браке либо в близком родстве или свойстве с учредителями, главными бухгалтерами или руководителями организаций, в отношении которых предполагается актуарная проверка и оценка.

Но считаю, что указанных ограничений недостаточно для независимости указанного субъекта, так как ответственный актуарий может работать в организации по трудовому договору, не являясь ни учредителем, ни руководителем, ни бухгалтером. В этом случае все равно имеется зависимость актуария от интересов работодателя. Так работодатель 
имеет различные рычаги воздействия, финансовые, дисциплинарные и другие, на своих сотрудников, в том числе и на актуария. Поэтому под влиянием и напором руководства актуарий может делать необъективные и заведомо ложные заключения, но удовлетворяющие интересы организации.

Безусловно, каждый актуарий должен при выполнении своих функций соблюдать кодекс профессиональной этики и обосновывать свои выводы согласно положениям методик и стандартов. Однако работая по трудовому договору, его заключение всегда будет положительным, составленным в интересах организации работодателя. При этом формально оно будет соответствовать всем нормам.

В связи с изложенным, полагаю, что независимость актуария можно достичь только путем законодательного запрета на работу ответственного актуария по трудовому договору. Безусловно, каждая организация может иметь в своем штате актуариев, но выдавать самостоятельно себе заключение неправильно. Это все равно что, если бы юридические лица проводили в отношении себя аудиторскую проверку и давали заключение о положительном финансовом положении компании и соответствии всей отчетности действительности и правовым нормам.

При исследования данной темы также считаю необходимым выделить еще одну проблему, которая касается содержательной части актуарного заключения, его целей и задач.

Согласно ст. 5 Ф3 "Об актуарной деятельности" актуарное заключение должно содержать ответ на задачу, которая была поставлена перед ответственным актуарием, результаты актуарных расчетов, необходимые для обоснования выводов актуарного заключения, выводы и рекомендации по устранению выявленных недостатков. Кроме того, выводы, сделанные в актуарном заключении, могут быть не точными и носить вероятностный характер.

В связи с вышеизложенным можно сделать вывод, что, законодателем не установлены строгие и четкие требования к актуарному заключению. Так остается нерешенным вопрос, постановки задачи актуарию при проведении исследования, не ясно какого характера он должен быть. Также, не понятно, что должно содержаться в актуарном заключении. Думается, что ни законодатель, ни Центральный банк РФ не выработали четкой позиции относительно того, что должно содержать такое заключение, а, следовательно, до сих пор не ясна и цель проведения актуарного исследования.

Из выявленной проблемы следует, что в настоящее время актуарий работает формально, выполняя свои функции по своему субъективному усмотрению. В связи с этим также нарушается беспристрастность актуария при оценке финансовых рисков, ввиду того, что он может адаптировать свои выводы под интересы и потребности оцениваемого предприятия. А нарушения в этой части крайне сложно выявить, так как не установлены строгие требования к заключению.

В заключение хотелось бы сделать выводы, и выразить предложения по устранению проблем, выявленных в нашем исследовании.

Во-первых, необходимо решить вопрос профессиональной подготовки актуариев, так как в данный момент такая подготовка осуществляется только в некоторых субъектах РФ. В отдаленных регионах России, например, на Дальнем Востоке вообще не идет речи о подготовке такого рода специалистов. Понятно, что, так или иначе, экзамены все актуарии будут сдавать в Москве, однако считаем целесообразным осуществлять подготовку 
актуариев в регионах, по месту жительства. В связи с изложенным, считаем необходимым разработать учебные программы по подготовке актуариев в учебных заведениях всех регионов.

Во-вторых, считаю целесообразным исключить возможность ответственного актуария работать по трудовому договору, что позволит данному субъекту осуществлять деятельность объективно, не руководствуясь интересами работодателя. Этим вовсе не предлагается ограничить право организации иметь в своем штате актуариев, но выдавать актуарные заключения себе считаю абсурдным.

Деятельность актуариев, привлеченных по трудовому договору скорее нужна для текущего анализа работы организации. Но для сторонних лиц, особенно для уполномоченного органа, актуарное заключение должен готовить независимый специалист.

В-третьих, в ФЗ "Об актуарной деятельности" необходимо установить четкие и строгие правила проведения актуарного оценивания и составления актуарного заключения. В современных реалиях рассматриваемая деятельность также нуждается в установлении требований к содержанию актуарного заключения, полному составу и перечню задач, которые могут быть поставлены перед специалистом.

Таким образом, несмотря на принятие долгожданного Ф3 "Об актуарной деятельности", который определил понятия, правовой статус субъектов актуарной деятельности, все еще нельзя говорить об эфффективном осуществлении деятельности указанных субъектов. Имеется множество проблем, нуждающихся в разрешении, путем отмены некоторых правовых норм, внесения изменений в действующее законодательство, дополнительного нормативного регулирования.

1 Федеральный закон "Об актуарной деятельности в Российской Федерации" от 02.11.2013 N 293-Ф3 // "Российская газета" от 6 ноября 2013 г. № 249.

2 Четпаева Б. Б. Роль актуарии в повышении финансовой устойчивости страховых организаций. 2017. // URL: http://elibrary.ru/item.asp?id=21394663\& (дата обращения: 06.01.2020).

3 Козлова Е. В. Институт актуариев в свете российского законодательства // Теоретические основы экономических систем в современных условиях. 2015. С. 17-21.

4 Ефимова О.В. Некоторые особенности осуществления актуарной деятельности. 2018. // URL: http://elibrary.ru/item.asp?id=21784663\& (дата обращения: 06.01.2020).

\title{
PROBLEMS OF THE LEGAL STATUS OF ACTUARIUM AND IMPLEMENTATION OF ACTUARY ACTIVITY
}

\author{
(C) 2020 Kuznetsova Ekaterina Sergeevna \\ Student \\ Samara State University of Economics \\ E-mail: ek.cudryashova@yandex.ru
}

Keywords: risk, actuary, responsible actuary, actuarial opinion, self-regulatory organization.

The article is devoted to the analysis of the legal status of an actuary, including the problems encountered in the implementation of actuarial activities. The author considers these problems in aggregate and gives their general assessment, as well as suggests ways to solve them. 